\title{
Supramolecular Catalysis of a Catalysis-Resistant Diels-Alder Reaction: Rapid Dimerization of Cyclopentadiene inside Cucurbit[7] uril
}

\author{
Foad N. Tehrani, ${ }^{1}$ Khaleel I. Assaf, ${ }^{*, 1,2}$ Robert Hein, ${ }^{1}$ Thomas C. Nugent, ${ }^{1}$ Werner M. Nau ${ }^{*, 1}$ \\ ${ }^{1}$ Department of Life Sciences and Chemistry, Jacobs University Bremen, Campus Ring 1, 28759 Bremen, Germany. \\ ${ }^{2}$ Department of Chemistry, Faculty of Science, Al-Balqa Applied University, 19117 Al-Salt, Jordan.
}

In contrast to Diels-Alder reactions involving heteroatom-containing substrates, the endo dimerization of cyclopentadiene responds only very weakly to changes in microenvironment or the presence of potential catalysts (less than factor of 10 variation), although this pure hydrocarbon reaction has been used as an early model to predict the maximum possible catalytic effect $\left(k_{\text {cat }} / k_{\text {uncat }}\right.$ ca. $\left.10^{6} \mathrm{M}\right)$ due to entropic contributions of a transition-state confinement (Page, M. I.; Jencks, W. P. Proc. Natl. Acad. Sci. USA 1971, 68, 1678). In the presence of cucurbit[n]uril homologues the reaction is selectively and almost maximally $\left(k_{\text {cat }} / k_{\text {uncat }}\right.$ ca. $\left.4 \times 10^{5} \mathrm{M}\right)$ accelerated by the intermediary sized cucurbit[7]uril in aqueous solution, while the other macrocyclic homologues display no acceleration or an inhibitory effect. The expected product inhibition due to the strong binding of the dicyclopentadiene reaction product can be overcome by addition of $10 \%$ methanol, which affords catalytic turnover numbers above 10 . The reaction was monitored using ${ }^{1} \mathrm{H}$ NMR spectroscopy as well as UV spectrophotometry. The analysis of the kinetic data, combined with packing coefficient considerations, modelling of Lennard-Jones potentials, and dispersion-corrected DFT calculations, suggest that the catalysis is due to an entropy-dominated transition-state stabilization in the tightly packed ternary complex. 


\section{Introduction}

Arguably, at least to an outsider, there is no area in catalysis which has been less practically relevant and at the same time more conceptually insightful than supramolecular catalysis with macrocycles. ${ }^{1-3}$ The absence of successful application examples neither in industrial chemistry nor in synthetic methodology is contrasted by a wealth of advancements in regard to the understanding of the fundamental roles of effective molarity, substrate preorganization, transition-state stabilization, competitive binding, and product inhibition. ${ }^{4,5}$ The reason that macrocycles such as cyclodextrins, calixarenes, cyclophanes, cavitands, capsules, molecular metallacages, and cucurbiturils have moved into the focus is that they have been considered as potential mimics of active sites which could eventually rival enzymatic functionality. ${ }^{5-21}$ Concomitantly, Diels-Alder reactions ${ }^{22-25}$ emerged as the gold standard to benchmark the catalytic activity of macrocycles., ${ }^{7,913,19,26-30}$ In all case studies on supramolecular catalysis of Diels-Alder reactions, substrates with activating groups containing heteroatoms have been studied which are strongly dependent on the solvent environment or the presence of (Lewis) acidic or basic functional groups..$^{31,32}$

a)

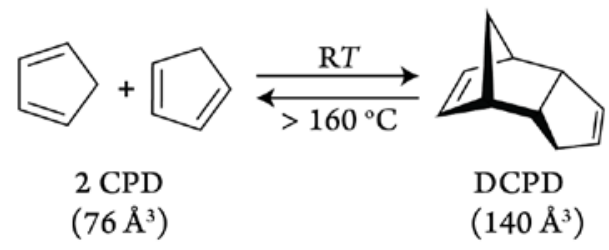

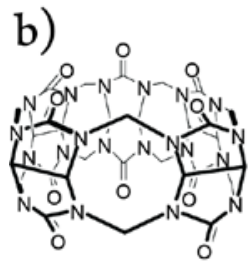

CB5 $\left(63 \AA^{3}\right)$

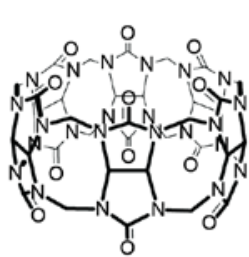

CB6 $\left(142 \AA^{3}\right)$

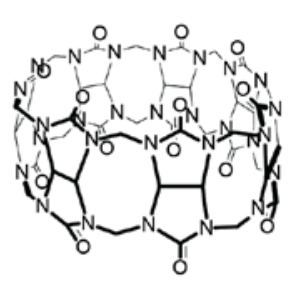

CB7 $\left(242 \AA^{3}\right)$

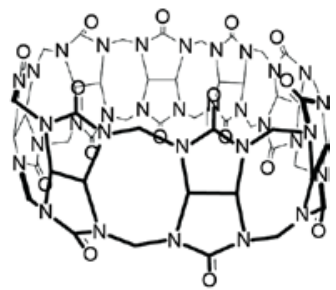

CB8 $\left(367 \AA^{3}\right)$

Chart 1. a) Diels-Alder reaction of cyclopentadiene, CPD, to endo-dicyclopentadiene, DCPD. b) Molecular structures of cucucurbit $[n]$ urils, $\mathrm{CB} n, n=5-8$; molecular volumes and volumes of the inner cavity are given in parentheses.

The dimerization of cyclopentadiene (CPD) is the prototype of a Diels-Alder reaction of a simple hydrocarbon that follows the endo rule (Chart 1). At the same time, it is the textbook example of a Diels-Alder reaction that is extremely difficult to accelerate through the choice of the 
reaction conditions; ${ }^{33}$ the use of ionic liquids with $60 \% \mathrm{AlCl}_{3}{ }^{34}$ leads only to a 6-fold rate enhancement, while ultrasound does not even reach a factor of $2 .^{35}$ This leaves only the universal possibility of increasing temperature or, since Diels-Alder reactions have negative volumes of activation, high pressure to speed up this slow reaction. ${ }^{24}$ Moreover, in none of the numerous examples involving supramolecular catalysis of Diels-Alder reactions between heteroatom-

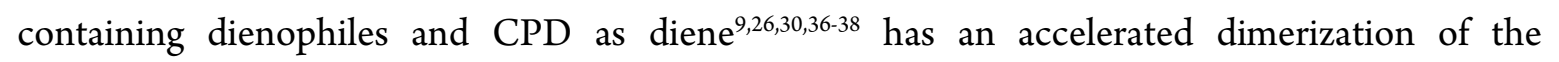
hydrocarbon been reported as an interfering side reaction. Accordingly, CPD dimerization has evaded, as other bimolecular reactions involving solely hydrocarbon substrates, noteworthy rate enhancements by means of supramolecular catalysis.

This "catalysis resistance" is striking, because the dimerization of CPD has been introduced 50 years ago by Page and Jenks as the theoretical target for biomimetic rate enhancements that could be traced back to a preferential binding of transition states and that could, on paper, reach $k_{\text {cat }} / k_{\text {uncat }}$ values up to $10^{6} \mathrm{M} \cdot{ }^{39}$ This maximum has never been reached in the five decades to come, even when using the more amenable heteroatom-containing Diels-Alder substrates (100$1000), 9,13,19,28,40-42$ and also our presently reported value of $4 \times 10^{5} \mathrm{M}$, achieved by employing cucurbit[7] uril (CB7, Chart 1) in water as additive, comes only close. While an efficient catalyst for CPD dimerization is now at hand, our study corroborates the very stigma of the research field: One can hardly imagine a less useful catalyst than one for an ancient reaction that is well known to proceed slowly but smoothly on its own at ambient temperature on an industrial as well as laboratory scale. ${ }^{43}$ 
Table 1. Rate constants for CPD dimerization under different reaction conditions. ${ }^{a}$

\begin{tabular}{lccccc}
\hline \hline & $\begin{array}{c}{[\mathrm{CPD}] /} \\
\mathrm{mM}\end{array}$ & $\begin{array}{c}{[\mathrm{CB} n] /} \\
\mathrm{mM}\end{array}$ & $\begin{array}{c}k_{\text {app }} / 10^{-6} \\
\mathrm{M}^{-1} \mathrm{~s}^{-1 \mathrm{~b}}\end{array}$ & $t / \mathrm{h}$ & Conv./ $\%^{\mathrm{c}}$ \\
\hline Neat & $11.9 \times 10^{3}$ & 0 & $0.90^{\mathrm{d}}$ & 4 & 14 \\
$\mathrm{H}_{2} \mathrm{O}$ & 4.0 & 0 & 7.2 & 360 & 3.6 \\
$\mathrm{CB} 5$ & 2.0 & 4.0 & 9.4 & 504 & 3.4 \\
$\mathrm{CB}^{\mathrm{e}}$ & 1.1 & 0.4 & $<5$ & 504 & $<0.5$ \\
$\mathrm{CB}^{\mathrm{e}}$ & $\mathbf{3 . 0}$ & $\mathbf{3 . 0}$ & $\mathbf{1 . 4} \times \mathbf{1 0}^{\mathrm{s}}$ & $\mathbf{1}$ & $\mathbf{6 0}$ \\
$\mathrm{CB}^{\mathrm{e}}$ & 0.3 & 0.3 & $<9$ & 504 & $<0.5$ \\
\hline \hline
\end{tabular}

${ }^{\text {a }}$ Measured by ${ }^{1} \mathrm{H}$ NMR in $\mathrm{D}_{2} \mathrm{O}$ at $25^{\circ} \mathrm{C}$ (see Figure S2); rate constants were determined by plotting $1 /[\mathrm{CPD}]$ against time according to $1 /[\mathrm{CPD}]=1 /\left[\mathrm{CPD}_{0}\right]+k_{\mathrm{app}} t .{ }^{\mathrm{b}} 10 \%$ error. ${ }^{\mathrm{c}}$ Error in conversion is $5 \%$ of stated values. ${ }^{\mathrm{d}}$ Literature value: $0.83 \times 10^{-6} \mathrm{M}^{-1} \mathrm{~s}^{-1}$, from ref. ${ }^{44}$; same value determined by UV spectrophotometry. ${ }^{\text {e }} 20 \mathrm{mM}$ and $50 \mathrm{mM} \mathrm{NaCl}$ were used to increase the solubility of $\mathrm{CB} 6$ and $\mathrm{CB} 8$, respectively. ${ }^{\mathrm{f}}$ Measured at $\mathrm{pH} 3.3$, which is the $\mathrm{pH}$ obtained when dissolving $3 \mathrm{mM} \mathrm{CB7}$ due to residual acid from its synthesis; the $\mathrm{pH}$ was not found to affect the reaction rate between $\mathrm{pH}$ 1.5-7.5.

\section{Results and Discussion}

The Diels-Alder reaction of CPD can be conveniently monitored by ${ }^{1} \mathrm{H}$ NMR (Figure 1 and Figure S2) or, alternatively, by UV (see Figures S5-S8). Neat CPD dimerizes slowly, with a rate of $9.0 \times 10^{-7} \mathrm{M}^{-1} \mathrm{~s}^{-1}$, and this bimolecular reaction is known to vary only slightly in the gas phase $\mathrm{e}^{45}$ as well as a large range of solvents (factor of 3),,$^{33,46-50}$ while we find an eight-fold increased rate in water (Table 1). ${ }^{51}$ We next investigated the effects of $\mathrm{CB} n$ macrocycles. $\mathrm{CB} n$ are known for their high affinities to guest molecules, ${ }^{52-54}$ driven by the hydrophobic effect for inner-cavity binding ${ }^{53,55-}$ 58 and by cation-dipole interactions with the carbonyl portals. $18,54,56,59,60$ In fact, guests with ammonium anchoring groups have been previously designed and studied with respect to catalytic reactions, ${ }^{8,15,16,18-20,38,61-67}$ including the early [3+2] azide/alkyne cycloaddition example ${ }^{8,68}$ of a reaction type which has later been referred to as (in-situ) click chemistry. ${ }^{69}$ Their water solubility displays an even-odd anomaly, which limits the accessible concentrations of the even homologues. ${ }^{59,70}$ 


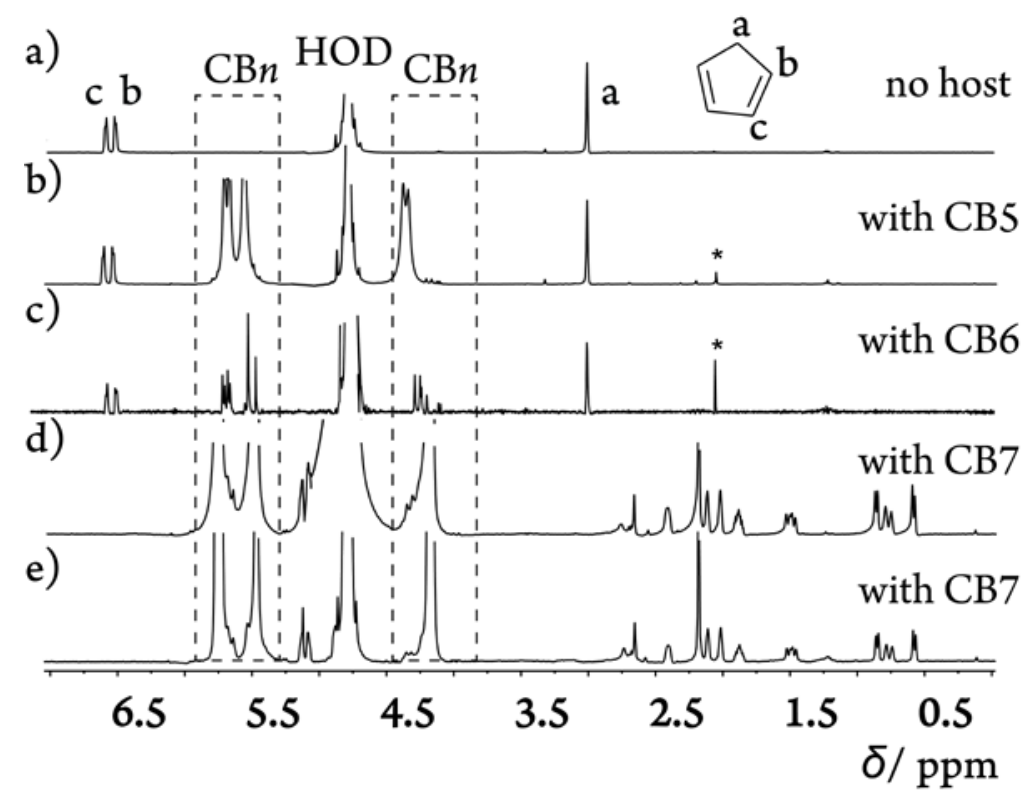

Figure 1. Dimerization of CPD (3 mM) monitored by ${ }^{1} \mathrm{H}$ NMR after $24 \mathrm{~h}$ a) as neat substrate in $\mathrm{D}_{2} \mathrm{O}$ (no reaction), $\mathrm{b}$ ) in the presence of CB5 (no reaction), c) in the presence of CB6 (in $20 \mathrm{mM}$ $\mathrm{NaCl}$, a complex was formed without reaction), d) in the presence of $\mathrm{CB} 7$ (rapid dimerization). Panel e) shows the ${ }^{1} \mathrm{H}$ NMR spectrum of DCPD complexed with CB7, which matches the one for product formation with $\mathrm{CB} 7$. Asterisk marks residual acetone from $\mathrm{CB} n$ synthesis.

In the presence of CB5, which is too small to encapsulate the substrate, ${ }^{71}$ the ${ }^{1} \mathrm{H}$ NMR showed no changes of the CPD peaks, and no product was detected after $24 \mathrm{~h}$ (Figure $1 \mathrm{~b}$ ). The rate of CPD dimerization in the presence of CB5 remains similar to that in water (Table 1), where ca. $3.5 \%$ conversion was measured after $2-3$ weeks. CB6 is sufficiently large to encapsulate an individual CPD molecule, ${ }^{55}$ as confirmed by a slight up-field shift of the CPD protons and a splitting of the CB6 signals (Figure 1c). A CB6-isolated CPD substrate is inaccessible to dimerization and, expectedly, addition of CB6 inhibited the reaction markedly (Figure 1c). However, an equimolar amount of the intermediary sized CB7 accelerated the reaction by ca. 5 orders of magnitude, taking the dimerization in the neat liquid as reference point and using apparent bimolecular rates for an initial kinetic comparison ( $k_{\text {app }}$ values in Table 1 and Figure 2a). The conversion of CPD to DCPD in the presence of CB7 was sufficiently fast to allow ${ }^{1} \mathrm{H}$ NMR monitoring (Figure S2). A new set of peaks in the aliphatic region was observed after $24 \mathrm{~h}$, which was assigned to the host-encapsulated dimerization product, endo-dicyclopentadiene (DCPD, 
Figure 1d). Product identity was verified by ${ }^{1} \mathrm{H}$ NMR (Figure 1e) and GC. Finally, the use of the larger CB8 macrocycle shows, at best, a slight inhibitory activity, relative to water (Table 1). It immediately transpires that the size of the encapsulating macrocyclic cavity is critical to enable supramolecular catalysis of this previously catalysis-resistant Diels-Alder reaction. It should be noted that the high endo diastereoselectivity was retained under all reaction conditions, ${ }^{22,72,73}$ that is, no exo product was detected.

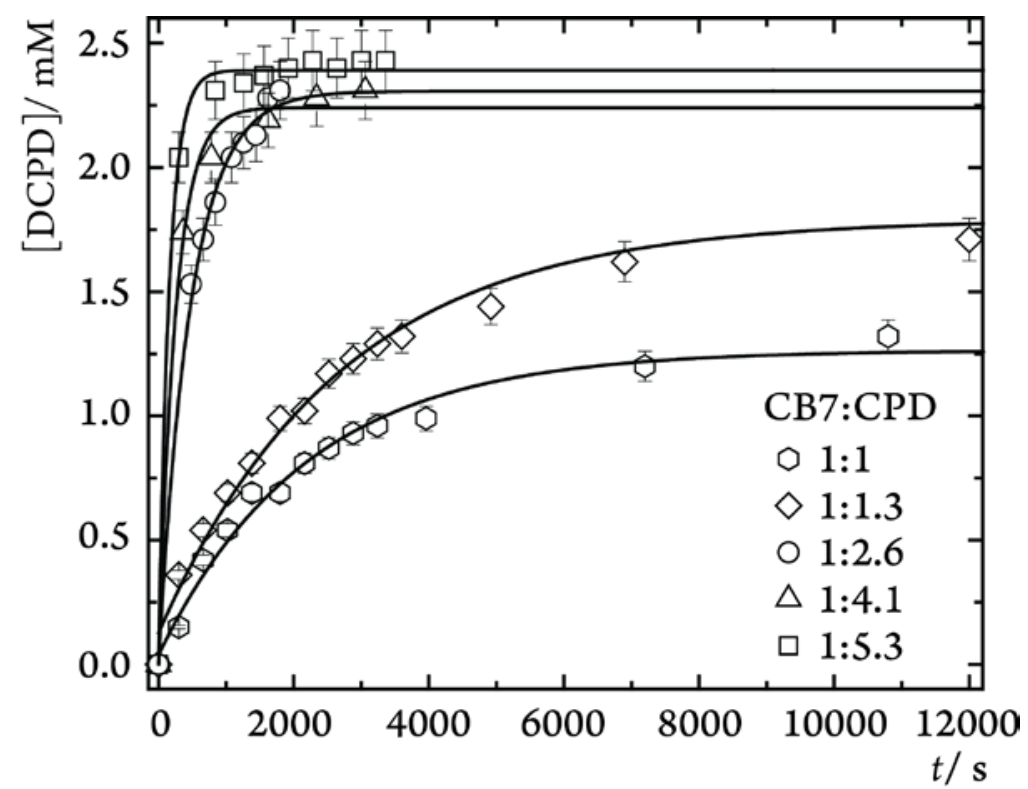

Figure 2. ${ }^{1} \mathrm{H}$ NMR monitoring of $\mathrm{DCPD}$ formation with time at different $\mathrm{CB} 7: \mathrm{CPD}$ concentration ratios (2.5 mM CB7, 2.5-13.3 mM CPD, pH 3.3).

We analyzed the catalytic action of CB7 in further detail. The variation of the concentration ratio between substrate and catalyst (Figure 2b) showed that the largest initial reaction rates were observed at a more than two-fold excess of the substrate, which pointed to the formation of a ternary host-guest complex, as required for dimerization. Moreover, while the rate increased with CPD concentration, the conversion stopped near a common plateau, which pointed to product inhibition, ${ }^{26,41,74-76}$ that is, DCPD shows stronger cavity binding than CPD, which inhibits further reaction and catalytic turn-over. This complication is a general problem in macrocyclic catalysis involving Diels-Alder reactions, in which the (late) transition state is highly ordered and structurally resembles more the product than the reactants. ${ }^{26,41,63,75,77-80}$ To overcome product inhibition, various "tricks" have been developed, such as domino reactions of the intermediary products to afford noncompetitive guests. ${ }^{13,40,76,79,81,82}$ In our case, catalytic turnover could be 
achieved through a complementary strategy, namely the choice of a slightly less polar solvent mixture (addition of $10 \%$ methanol). Practically, this lowers the binding constant of the more hydrophobic DCPD to CB7 sufficiently (from $4.8 \times 10^{7} \mathrm{M}^{-1}$ in water to $9.0 \times 10^{5} \mathrm{M}^{-1}$ in water:methanol 9:1, measured by ITC and indicator displacement titrations, see Figure S9) to allow the reaction to proceed with a turnover number of 10 or higher (Figure 3). As expected for catalytic reactions inside macrocyclic cavities, the addition of a strong competitive binder for CB7, namely adamantylamine, ${ }^{18,58,83}$ caused quantitative inhibition of dimerization (see Figure S3).

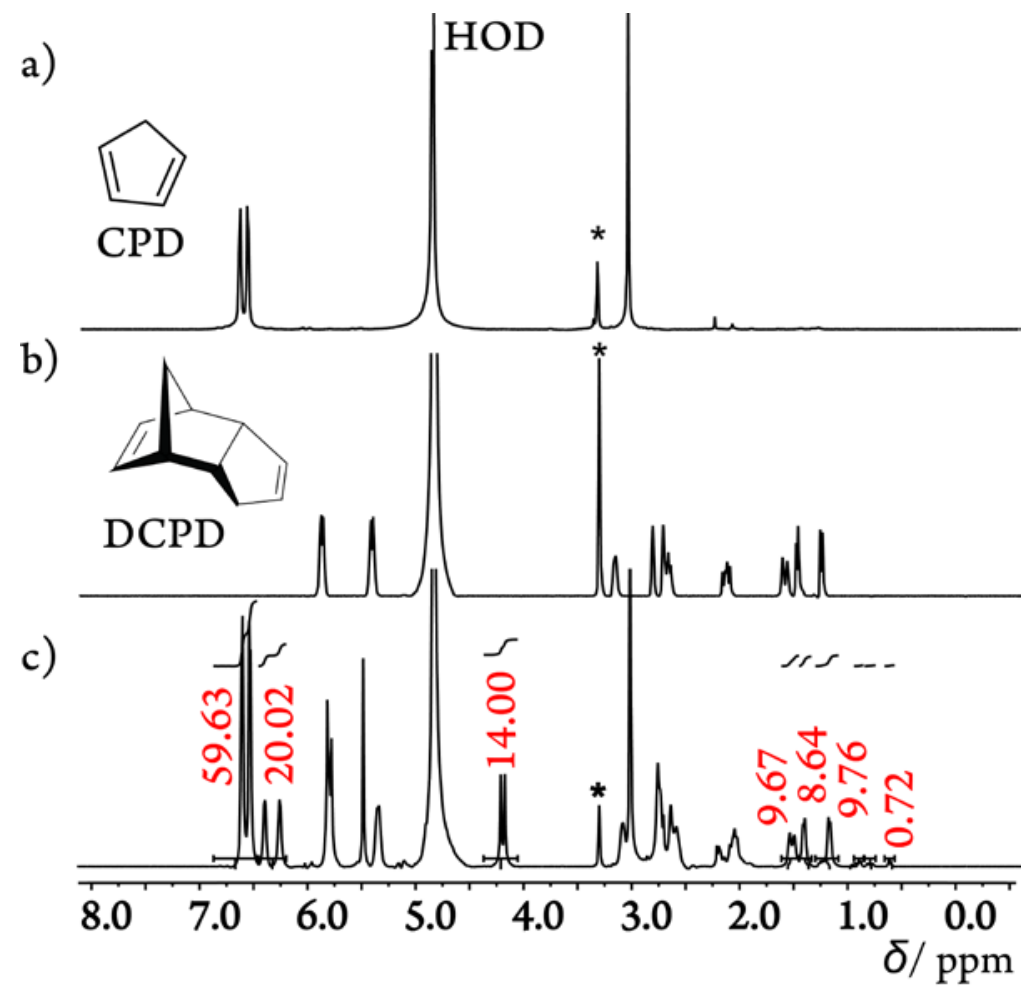

Figure 3. ${ }^{1} \mathrm{H}$ NMR spectra in $\mathrm{D}_{2} \mathrm{O}: \mathrm{CD}_{3} \mathrm{OD} 9: 1$ mixtures after 24 h. a) $\mathrm{CPD}(30 \mathrm{mM})$; no product was formed. b) DCPD (10 mM). c) CPD (120 mM) dimerization inside the cavity of CB7 (3 $\mathrm{mM}$ ); catalytic turnover was observed and $~ 30 \mathrm{mM} \mathrm{DCPD}$ was formed. Asterisk marks $\mathrm{MeOH}$. 


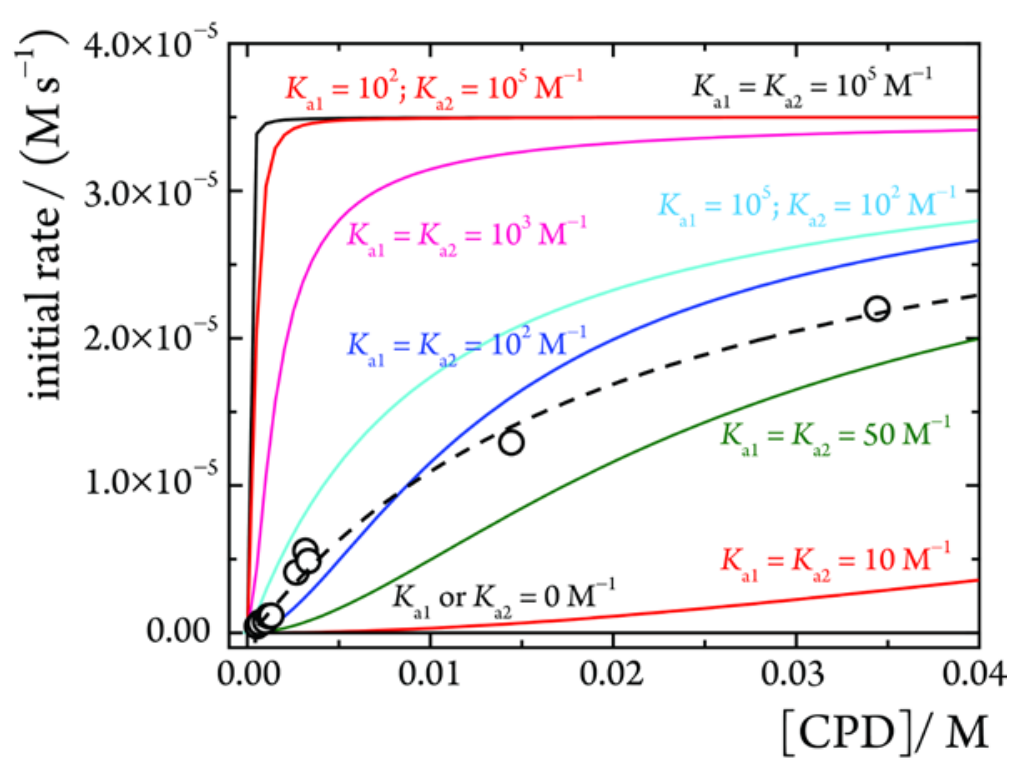

Figure 4. Simulated kinetics for the CPD dimerization inside CB7 (0.10 mM) assuming different sets of binding constants. Open circles show the experimental CPD dimerization rates, determined by UV spectrophotometry in a 9:1 $\mathrm{H}_{2} \mathrm{O}: \mathrm{CH}_{3} \mathrm{OH}$ mixture as a function of CPD concentration and the best fit to the kinetic model is shown by the dashed line. See Supplementary Information for fitting and simulation equation.

In order to quantify the catalytic effect, we performed a kinetic analysis under conditions where product inhibition could be largely neglected. In detail, we analyzed the dependence of the initial rates of the catalytic reaction on the substrate concentrations in the presence of $10 \%$ methanol with excess $\mathrm{CPD},{ }^{30}$ see Figure 4. In the kinetic modeling, the formation of a ternary complex with a first $\left(K_{\mathrm{a}, 1}\right)$ and a second $\left(K_{\mathrm{a} 2}\right)$ binding constant is considered, from which an irreversible chemical reaction with a unimolecular rate constant $\left(k_{\text {cat }}\right)$ occurs. A scenario with $K_{\mathrm{a} 1}=$ $1.4 \times 10^{4} \mathrm{M}^{-1}$ and $K_{\mathrm{a} 2}=46 \mathrm{M}^{-1}$ provided the best fit, which is also reasonable in relation to the experimentally accessible binding constant of cyclopentane to CB7 $\left(K_{\mathrm{a}}=1.96 \times 10^{5} \mathrm{M}^{-1}\right.$, note that alkanes tend to show stronger affinities than alkenes). ${ }^{53,55}$ Unfortunately, the binding constants for the formation of the ternary complex $\left(K_{\mathrm{a} 1}\right.$ and $\left.K_{\mathrm{a} 2}\right)$ could not be independently obtained through either ${ }^{1} \mathrm{H}$ NMR titrations or isothermal titration calorimetry (ITC), because of the rapidly occurring dimerization. The $k_{\text {cat }}$ value for dimerization inside the ternary CB7 complex, which would correspond to the plateau value in Figure $4\left(k_{\text {cat }}[\mathrm{CB} 7]\right)$, was found to be $0.35 \pm 0.04 \mathrm{~s}^{-1}$. This corresponds to a catalytic effect $\left(k_{\text {cat }} / k_{\text {uncat }}\right)$ of $4 \times 10^{5} \mathrm{M}$, when referenced to the bimolecular 
reaction rate in the neat liquid (Table 1); this value comes close to the predicted maximum for this specific Diels-Alder reaction $\left(10^{6} \mathrm{M}\right) .{ }^{84}$

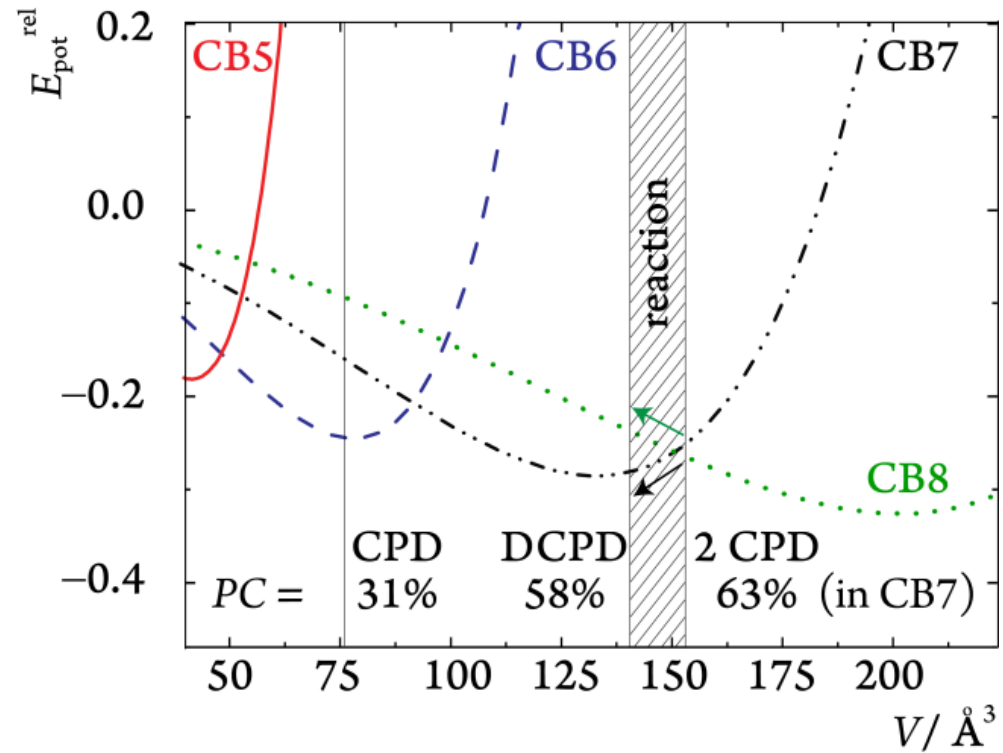

Figure 5. Model potentials for the interaction of a spherical guest positioned centrosymmetrically inside a host cavity versus guest volume (see ref. 16 for parameters and further details).

The catalysis and its selective observation for the intermediary sized host, CB7, can be empirically rationalized by packing coefficient considerations and modelling by Lennard-Jones type potentials, as applied in a previous gas-phase study for retro-Diels-Alder reactions (Figure 5). ${ }^{16}$ The dimerization of CPD occurs essentially with the same rate and activation energy in the gas phase and in solution, ${ }^{45}$ which strengthens the theoretical analysis. Note that the $\mathrm{CBn}$ molecular containers have varying inner cavity size and favor the binding of differently sized guest molecules, with maximal affinity always near the ideal packing coefficient $(P C=55 \%)$, the same as that found for the neat CPD liquid. ${ }^{56,85}$ Even a single CPD molecule $\left(V=76 \AA^{3}\right)$ is too large to bind to CB5, such that this macrocycle acts as a bystander in the dimerization (Table 1). CB6 can complex a single substrate molecule only, and thereby retards the reaction. CB7 and CB8 are both sufficiently large to encapsulate two CPD molecules (negative $E_{\mathrm{pot}}$ ) but there is a fundamental difference in respect to the effects that the macrocycles have on the energy profile of the innerphase dimerization reaction (arrows in Figure 5). From the molecular volumes of the substrates $\left(2 \times 76 \AA^{3}\right)$ within the available cavity space of CB7 $\left(242 \AA^{3}\right)$ one can estimate a PC value of $63 \%$ 
for the ternary complex. This means that for CB7, the dimerization occurs in the tight-packing regime $(P C>55 \%)$, which leads to a transition-state stabilization $(P C=60 \%)$ as the reaction proceeds to the product, which finds itself almost in an ideal packing state $(P C=58 \%)$. This accounts for the experimentally observed catalysis with product inhibition. For CB8, the reaction proceeds in the loose-packing regime $(<55 \%)$; in this case, a further contraction in guest volume along the reaction coordinate decreases (from $41 \%$ to $38 \%$ ) rather than increases the overall complex stability, in line with the observed (slight) inhibition of the dimerization reaction.

Beyond the empirical reasoning, the dimerization of CPD allows a particularly rigorous analysis of several other putative factors that could contribute to the observed catalysis inside CB7 and, in particular, it allows us to exclude several "trivial" causes. First, because the reaction is abundantly known to be largely insensitive to solvent properties, ${ }^{33,46-48}$ neither the low polarity of the CB7 cavity (estimated to be similar to that of $n$-octanol, $\varepsilon=10.3)^{86}$ nor its low polarizability (estimated to be below that of perfluorohexane, $P=0.12)^{87}$ can account for the rate acceleration. Second, the reaction is unique in that it also proceeds in neat solution (Table 1), such that effects due to an enhanced local concentration inside CB7 can be convincingly excluded as being dominant: The concentration of CPD in the neat liquid is 4000 times higher than that tested in the presence of $\mathrm{CB} 7$, but its conversion is more than a factor of 4 lower, despite a 4 times longer reaction time. In fact, even by considering the tighter packing of CPD inside $\mathrm{CB} 7$ than in the neat liquid ( $63 \%$ versus $55 \%$, see above), the local concentration in the cavity ( $13.6 \mathrm{M}$ ) is only slightly higher than that in the neat liquid $(11.9 \mathrm{M})$, such that this effect is neglected.

Third, physicochemical properties of hydrocarbons are exceptionally well researched, such that not only the compressibility of CPD is well known, ${ }^{88}$ but also the pressure dependence of its dimerization. ${ }^{89}$ The increase in local concentration and packing of CPD inside CB7 (by ca. 15\%) has the pertinent consequence of a strong increase in internal pressure inside the CB7 cavity, which is expected to accelerate the reaction due to its negative volume of activation ( $V^{\ddagger}$ ca. 20 $\left.\mathrm{cm}^{3} \mathrm{~mol}^{-1}\right) \cdot{ }^{89}$ From the known compressibility of $\mathrm{CPD},{ }^{88}$ a $15 \%$ increased density can be correlated to a "mechanical" pressure of ca. 3 kbar experienced in the ternary complex. The inner phase of macrocycles has been frequently associated with unusual physical or phase properties, ${ }^{87,90-93}$ and the specific idea that guests encapsulated inside macrocyclic cavities can experience an enhanced 
internal pressure up to $10 \mathrm{kbar}$ has been described, among others, by Rebek. ${ }^{94}$ Note that such complexes in the tight packing regime may still experience an overall stabilization on the LennardJones potential (Figure 5) - even diamantane, a C14 hydrocarbon (packing coefficient 79\%), is stabilized inside $\mathrm{CB}^{52,58}$ - such that elevated internal pressures inside macrocycles can be formally assigned. The absolute value of $3 \mathrm{kbar}$ is, however, only expected to result in a rate enhancement by a factor of ca. 12 near ambient temperature, according to the known pressure dependence of dimerization of neat CPD. ${ }^{89}$ Accordingly, these three factors are at best circumstantial ones and another main one must be responsible for the observed 5 orders of magnitude enhancement in rates. To identify the cause, we resorted to computational modelling, akin to previous theoretical studies of reactions inside molecular containers. ${ }^{30,95-99}$

We chose the $\mathrm{wB} 97 \mathrm{XD} / 6-31 \mathrm{G}^{*}$ level of theory, because it corrects for dispersion effects relevant in host-guest complexes, ${ }^{16}$ and, as a density functional theory (DFT) method, is known to perform well for Diels-Alder transition states. ${ }^{100} \mathrm{We}$ did not include solvation models, because of the small solvent effects for the CPD dimerization and because of the constrictive binding by the CB7 macrocycle, which effectively insulates fully immersed guests from the outer environment. ${ }^{87,101}$ As another asset, CPD dimerization has been studied in the gas phase, ${ }^{45}$ such that direct benchmarking is possible. Indeed, the DFT calculations predict an activation enthalpy of $17.8 \mathrm{kcal} \mathrm{mol}^{-1}$ for the endo dimerization of free CPD in the gas phase (Table 2), which compares well with the experimental activation energy in the gas phase as well as that in solution (ca. $\left.17 \mathrm{kcal} \mathrm{mol}^{-1}\right) \cdot{ }^{48,102}$ 


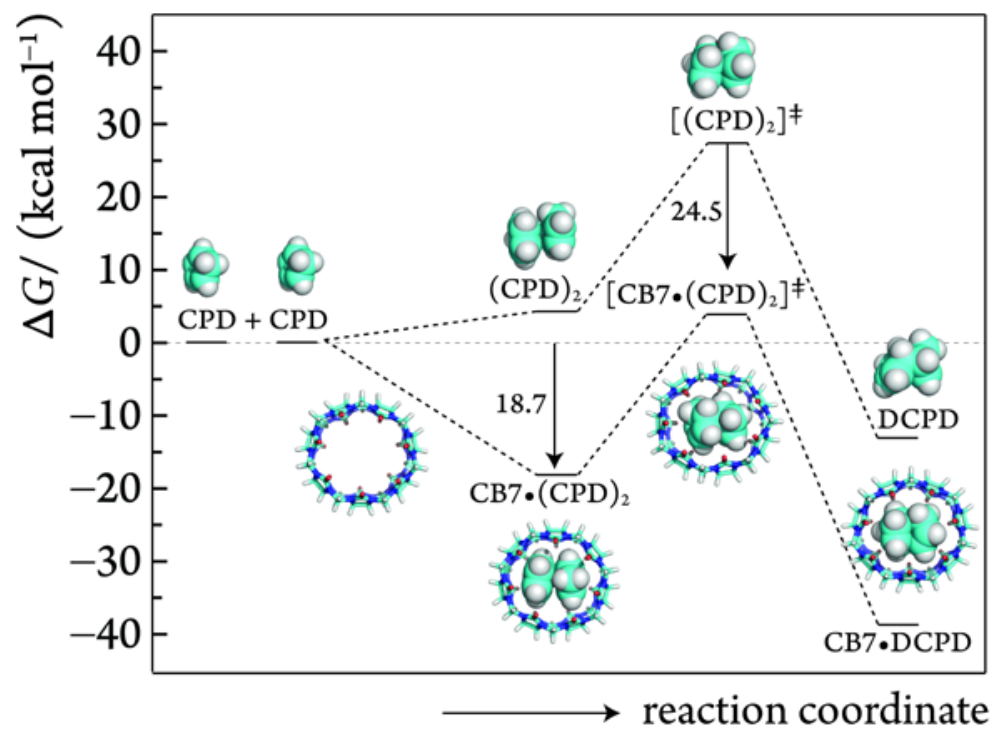

Figure 6. Calculated reaction coordinate $\left(\mathrm{wB} 97 \mathrm{XD} / 6-31 \mathrm{G}^{*}\right.$, gas phase) with the relative free energies of the reactants $(\equiv 0)$, dimerization transition states, and products for the CPD dimerization reaction of free versus CB7-complexed CPD.

Table 2. DFT-calculated (wB97XD/6-31G*) thermodynamic data of the exo and endo transition states for dimerization of free versus CB7-complexed CPD (gas phase, in $\mathrm{kcal} \mathrm{mol}^{-1}$; calculated for the Ben-Naim reference state, see ref. ${ }^{58,103}$.

\begin{tabular}{lccc}
\hline \hline \multicolumn{5}{c}{$\Delta H^{\ddagger}$} & $T \Delta S^{\ddagger}$ & $\Delta G^{\ddagger}$ \\
\hline 2 CPD free & & \\
\hline endo TS & 17.8 & -9.5 & 27.3 \\
exo TS & 21.2 & -9.3 & 30.5 \\
\hline CB7•(CPD $)_{2}$ ternary complex \\
\hline endo TS & 20.8 & -0.7 & 21.5 \\
exo TS & 22.3 & -1.9 & 24.2
\end{tabular}

The calculation of the free energies along the reaction coordinate in Figure 6 compares the (endo) Diels-Alder reaction for free CPD (top) with the CB7-assisted counterpart (bottom). The CB7-encapsulation related stabilization of two CPD molecules $\left(18.7 \mathrm{kcal} \mathrm{mol}^{-1}\right)$ is smaller than those of the transition state and product (both ca. $25 \mathrm{kcal} \mathrm{mol}^{-1}$ ), in line with the empirical Lennard-Jones modelling (Figure 5) and accounting for both key aspects, the effective catalysis 
and product inhibition. Assuming that the dispersion interactions between the guest(s) and the CB7 host remain similar or even decrease slightly due to the negative reaction volume, this difference reflects the tighter packing in the substrate complex as a consequence of increased steric interactions (Pauli repulsion), which is being alleviated as the reaction proceeds. This effect can either be interpreted in terms of a destabilization of the reactants ("strain activation"), ${ }^{8}$ a transition-state stabilization, ${ }^{26,79}$ and partly in terms of a relief of internal pressure (see above). Interestingly, and fully in line with a preferential binding of the transition state, the size and shape of the CPD dimerization transition state resembles ferrocene, which binds strongly to $\mathrm{CB} 7$ ( $\mathrm{PC}=$ $\left.58 \%, K_{\mathrm{a}}>10^{6} \mathrm{M}^{-1}\right) .{ }^{56,101,104}$

Turning towards the reaction kinetics, the free energy of activation for the endo cyclization is predicted to lie $3 \mathrm{kcal} \mathrm{mol}^{-1}$ below that for exo cyclization in both the free and complexed form; indeed, no change in diastereoselectivity was experimentally observed in the presence of CB7. In regard to the observed catalytic rate enhancement for the endo cyclization, complexation by CB7 lowers the free energy of activation for the Diels-Alder reaction by ca. $6 \mathrm{kcal} \mathrm{mol}^{-1}$ (Table 2). While this value is subject to change as the level or type of the dispersion-corrected DFT method is being varied, the $\mathrm{wB} 97 \mathrm{XD} / 6-31 \mathrm{G}^{*}$ value compares reasonably well with the ca. $7.5 \mathrm{kcal} \mathrm{mol}^{-1}$ effective stabilization expected from the experimentally observed catalytic effect, calculated as $\operatorname{RT} \ln \left(k_{\text {cat }} / k_{\text {uncat }}\right)$.

Noteworthy, the activation enthalpy for cyclodimerization is calculated to increase by ca. $3 \mathrm{kcal}$ $\mathrm{mol}^{-1}$ in the ternary endo complex. This demonstrates that CB7 does not act as a perfect template as far as an accurate endo preorganization of the substrates is concerned, thereby disregarding this putative factor. However, the large unfavorable negative activation entropy calculated for the dimerization of neat CPD virtually vanishes upon complexation by $\mathrm{CB} 7$ (from $-9.5 \mathrm{kcal} \mathrm{mol}^{-1}$ to $-0.7 \mathrm{kcal} \mathrm{mol}^{-1}$ for the endo transition state, Table 2). This reveals that the catalysis is predominantly due to an entropic effect, in which CB7 acts primarily by a tight confinement of the substrate complex. ${ }^{8,101}$ The binding of the reaction partners in the tight packing regime $(P C>$ $55 \%)$ appears to be instrumental for this confinement effect to unfold. Because we employed a dispersion-corrected DFT method, we were also able to calculate the van der Waals-associated $(\mathrm{CPD})_{2}$ dimer as an energy minimum, without surrounding CB7 (Figure 6). This allowed us to 
assess the entropy loss due to dimer formation as $-7.2 \mathrm{kcal} \mathrm{mol}^{-1}(T \Delta S)$, which corresponds largely to the entropic advantage for the CPD dimerization inside CB7. Accordingly, because the experimental rate enhancement of the Diels-Alder reaction of CPD approaches the projected maximum, and because the DFT calculations confirm a large entropic advantage for the innerphase dimerization relative to the reaction of the unbound substrates, our experimental results may be seen as a late validation of the early theoretical work by Page and Jencks on the catalysis of CPD dimerization. ${ }^{39}$ As an overarching conclusion, dramatic rate enhancements for associative bimolecular reactions are in general expected for active sites that bind their substrates in the tightpacking regime.

\section{Conclusion}

We present a case of a supramolecular catalysis involving a cycloaddition of two pure hydrocarbon substrates, which complements previous examples of Diels-Alder reactions with the more environmentally and catalytically responsive heteroatom substrates. The dimerization of cyclopentadiene can be selectively and strongly accelerated by the intermediary sized cucurbit[7]uril in aqueous solution. The analysis of the catalytic reaction through several spectroscopic methods, as well as dispersion-corrected DFT calculations, packing coefficient consideration, and modelling of Lennard-Jones potentials rule out effective molarity or internal pressure as causes, but point to a clear-cut case of transition-state stabilization, thereby providing experimental confirmation of a prediction which has been made 50 years back. ${ }^{39}$

\section{Supplementary Information Available}

Any Supplementary Information and Source Data files are available in the online version of the paper.

\section{Author Information}

Corresponding Authors

*k.assaf@jacobs-university.de

*w.nau@jacobs-university.de 


\section{Acknowledgment}

This work was supported by the DFG within grant NA-686/8 as part of the priority program SPP 1807 “Control of London Dispersion Interactions in Molecular Chemistry" (W.M.N.).

\section{References}

(1) Meeuwissen, J.; Reek, J. N. H. Nat. Chem. 2010, 2, 615.

(2) Ballester, P.; Scarso, A. Front. Chem. 2019, 7.

(3) van Leeuwen, P. W. N. M.; Raynal, M. In In Supramolecular Chemistry in Water; Kubik, S., Ed.; Wiley-VCH Verlag GmbH \& Co. KGaA: 2020, p 525.

(4) Ballester, P.; Vidal-Ferran, A. In Supramolecular Catalysis; Ed.: P. W. N. M. van Leeuwen ed.; Wiley-VCH: Weinheim, 2008, p 1.

(5) Raynal, M.; Ballester, P.; Vidal-Ferran, A.; van Leeuwen, P. W. N. M. Chem. Soc. Rev. 2014, $43,1734$.

(6) Rideout, D. C.; Breslow, R. J. Am. Chem. Soc. 1980, 102, 7816.

(7) Sternbach, D. D.; Rossana, D. M. J. Am. Chem. Soc. 1982, 104, 5853.

(8) Mock, W. L.; Irra, T. A.; Wepsiec, J. P.; Manimaran, T. L. J. Org. Chem. 1983, 48, 3619.

(9) Kang, J. M.; Rebek J. Jr Nature 1997, 385, 50.

(10) Marty, M.; Clyde-Watson, Z.; Twyman, L. J.; Nakash, M.; Sanders, J. K. M. Chem. Commun. 1998, 2265.

(11) Warmuth, R. J. Inclusion Phenom. Macrocyclic Chem. 2000, 37, 1.

(12) Warmuth, R.; Kerdelhue, J. L.; Carrera, S. S.; Langenwalter, K. J.; Brown, N. Angew. Chem. Int. Ed. 2002, 41, 96.

(13) Yoshizawa, M.; Tamura, M.; Fujita, M. Science 2006, 312, 251.

(14) Kulasekharan, R.; Choudhury, R.; Prabhakar, R.; Ramamurthy, V. Chem. Commun. 201 1, 47, 2841.

(15) Pemberton, B. C.; Raghunathan, R.; Volla, S.; Sivaguru, J. Chem. Eur. J. 2012, 18, 12178.

(16) Lee, T. C.; Kalenius, E.; Lazar, A. I.; Assaf, K. I.; Kuhnert, N.; Grun, C. H.; Janis, J.; Scherman, O. A.; Nau, W. M. Nat. Chem. 2013, 5, 376.

(17) Zhang, Q.; Tiefenbacher, K. Nat. Chem. 2015, 7, 197. 
(18) Assaf, K. I.; Nau, W. M. Chem. Soc. Rev. 2015, 44, 394.

(19) Palma, A.; Artelsmair, M.; Wu, G.; Lu, X.; Barrow, S. J.; Uddin, N.; Rosta, E.; Masson, E.; Scherman, O. A. Angew. Chem. Int. Ed. 2017, 56, 15688.

(20) Funk, S.; Schatz, J. J. Inclusion Phenom. Macrocyclic Chem. 2020, 96, 1.

(21) Gaeta, C.; La Manna, P.; De Rosa, M.; Soriente, A.; Talotta, C.; Neri, P. ChemCatChem 2021, 13, 1638.

(22) Alder, K.; Stein, G. Angew. Chem. 1934, 47, 837.

(23) Sauer, J.; Sustmann, R. Angew. Chem. Int. Ed. 1980, 19, 779.

(24) Pindur, U.; Lutz, G.; Otto, C. Chem. Rev. 1993, 93, 741.

(25) Levandowski, B. J.; Raines, R. T. Chem. Rev. 2021, 121, 6777.

(26) Kang, J. M.; Hilmersson, G.; Santamaria, J.; Rebek J. Jr J. Am. Chem. Soc. 1998, 120, 3650.

(27) Kim, S. P.; Leach, A. G.; Houk, K. N. J. Org. Chem. 2002, 67, 4250.

(28) Horiuchi, S.; Murase, T.; Fujita, M. Chem. Asian J. 2011, 6, 1839.

(29) Xu, L.; Hua, W.; Hua, S.; Li, J.; Li, S. J. Org. Chem. 2013, 78, 3577.

(30) Martí-Centelles, V.; Lawrence, A. L.; Lusby, P. J. J. Am. Chem. Soc. 2018, 140, 2862.

(31) Otto, S.; Engberts, J. B. F. N.; Kwak, J. C. T. J. Am. Chem. Soc. 1998, 120, 9517.

(32) Vermeeren, P.; Hamlin, T. A.; Fernández, I.; Bickelhaupt, F. M. Angew. Chem. Int. Ed. 2020, $59,6201$.

(33) Reichardt, C. Solvents and Solvent Effects in Organic Chemistry; $3^{\text {rd }}$ Edition, Chapter 5; VCH: Weinheim, 2003.

(34) Kumar, A.; Pawar, S. S. J. Mol. Catal. A: Chem. 2004, 208, 33.

(35) Li, L.; Cai, Z.; Shen, B.; Xin, Z.; Ling, H. Chem. Eng. Technol. 2011 , 34, 1468.

(36) Dalla Cort, A.; Mandolini, L.; Schiaffino, L. Chem. Commun. 2005, 3867.

(37) Hatano, M.; Mizuno, T.; Izumiseki, A.; Usami, R.; Asai, T.; Akakura, M.; Ishihara, K. Angew. Chem. Int. Ed. 2011 , 50, 12189.

(38) Zheng, L. F.; Sonzini, S.; Ambarwati, M.; Rosta, E.; Scherman, O. A.; Herrmann, A. Angew. Chem. Int. Ed. 2015, 53, 13007.

(39) Page, M. I.; Jencks, W. P. Proc. Natl. Acad. Sci. USA 1971, 68, 1678.

(40) Kang, J. M.; Santamaria, J.; Hilmersson, G.; Rebek J. Jr J. Am. Chem. Soc. 1998, 120, 7389. 
(41) Nishioka, Y.; Yamaguchi, T.; Yoshizawa, M.; Fujita, M. J. Am. Chem. Soc. 2007, 129, 7000.

(42) Kusukawa, T.; Nakai, T.; Okano, T.; Fujita, M. Chem. Lett. 2003, 32, 284.

(43) Hazard note: At high concentrations, on a molar scale, in sealed containers or reactors, and without cooling, cyclopentadiene dimeriza-tion may lead to explosions, as they have actually occurred in an indus-trial settings, see am Ende, D. J.; Whritenour, D. C.; Coe, J. W. Org. Process Res. Dev. 2007, 11, 1141.

(44) Krupka, J. Pet. Coal 2010, 52, 290.

(45) Benford, G. A.; Khambata, B. S.; Wassermann, A. Nature 1937, 139, 669.

(46) Cöster, G.; Pfeil, E. Chem. Ber. 1968, 101, 4248.

(47) Swiss, K. A.; Firestone, R. A. J. Phys. Chem. A 1999, 103, 5369.

(48) Karpyak, N. M.; Makitra, R. G.; Marshalok, G. A.; Pal'chikova, O. Y.; Yatchishin, I. I. Russ. J. Gen. Chem. 2005, 75, 1712.

(49) J. B. Harkness; Kistiakowsky, G. B.; Mears, W. H. J. Chem. Phys. 1937, 5, 682.

(50) Kaufmann, H.; Wassermann, A. J. Chem. Soc. 1939, 870.

(51) There has been a controversy about the rate enhancement of this reaction in water, see Sangwan, N. K.; Schneider, H. J., J. Chem. Soc., Perkin Trans. 2 1989, 1223, Breslow, R.; Zhu, Z. N. J. Am. Chem. Soc. 1995, 117, 9923, Jorgensen, W. L.; Blake, J. F.; Lim, D. C.; Severance, D. L. J. Chem. Soc. Faraday Trans. 1994, 90, 1727, and Chandrasekhar S. J. Turkish Chem. Soc. Sect. Chem. 2017, 4, 899. Without entering an in-depth discussion, it can be readily demostrated by UV spectrophotometry (see Figure S6) that the values reported in these studies $\left(1.7 \times 10^{-2} \mathrm{M}^{-1} \mathrm{~s}^{-1} ; 3.6\right.$ $\times 10^{-4} \mathrm{M}^{-1} \mathrm{~s}^{-1}$ ) are too high, likely because the reactions were performed at very high CPD concentrations, and in part in saturated solution.

(52) Cao, L. P.; Šekutor, M.; Zavalij, P. Y.; Mlinaric-Majerski, K.; Glaser, R.; Isaacs, L. Angew. Chem. Int. Ed. 2014, 53, 988.

(53) Biedermann, F.; Nau, W. M.; Schneider, H.-J. Angew. Chem. Int. Ed. 2014, 53, 11158.

(54) Shetty, D.; Khedkar, J. K.; Park, K. M.; Kim, K. Chem. Soc. Rev. 2015, 44, 8747.

(55) Florea, M.; Nau, W. M. Angew. Chem. Int. Ed. 2011 , 50, 9338.

(56) Nau, W. M.; Florea, M.; Assaf, K. I. Isr. J. Chem. 2011, 51, 559. 
(57) Biedermann, F.; Uzunova, V. D.; Scherman, O. A.; Nau, W. M.; De Simone, A. J. Am. Chem. Soc. 2012, 134, 15318.

(58) Assaf, K. I.; Florea, M.; Antony, J.; Henriksen, N. M.; Yin, J.; Hansen, A.; Qu, Z.-w.; Sure, R.; Klapstein, D.; Gilson, M. K.; Grimme, S.; Nau, W. M. J. Phys. Chem. B 2017, 121, 11144.

(59) Lagona, J.; Mukhopadhyay, P.; Chakrabarti, S.; Isaacs, L. Angew. Chem. Int. Ed. 2005, 44, 4844 .

(60) Zhang, S.; Grimm, L.; Miskolczy, Z.; Biczók, L.; Biedermann, F.; Nau, W. M. Chem. Commun. 2019, 55, 14131.

(61) Jon, S. Y.; Ko, Y. H.; Park, S. H.; Kim, H.-J.; Kim, K. Chem. Commun. 2001, 1938.

(62) Wang, R. B.; Yuan, L. N.; Macartney, D. H. J. Org. Chem. 2006, 71, 1237.

(63) Klock, C.; Dsouza, R. N.; Nau, W. M. Org. Lett. 2009, 11, 2595.

(64) Y.-H. Wang, H. C., F.-F. Zhao, S.-F. Xue, Z. Tao, Q.-J. Zhu and G. Wei Catal. Commun. $2011,12,1127$.

(65) Zheng, L. F.; Sonzini, S.; Ambarwati, M.; Rosta, E.; Scherman, O. A.; Herrmann, A. Angew. Chem. Int. Ed. 2015, 53, 13007.

(66) Tang, B.; Zhao, J.; Xu, J.-F.; Zhang, X. Chem. Eur. J. 2020, 26, 15446.

(67) Li, G.; Trausel, F.; van der Helm, M. P.; Klemm, B.; Brevé, T. G.; van Rossum, S. A. P.; Hartono, M.; Gerlings, H. H. P. J.; Lovrak, M.; van Esch, J. H.; Eelkema, R. Angew. Chem. Int. Ed. 2021, 60, 14022.

(68) Mock, W. L.; Irra, T. A.; Wepsiec, J. P.; Adhya, M. J. Org. Chem. 1989, 54, 5302.

(69) Kolb, H. C.; Finn, M. G.; Sharpless, K. B. Angew. Chem. Int. Ed. 2001, 40, 2004.

(70) Masson, E.; Ling, X.; Joseph, R.; Kyeremeh-Mensah, L.; Lu, X. RSC Adv. 2012, 2, 1213.

(71) He, S.; Biedermann, F.; Vankova, N.; Zhechkov, L.; Heine, T.; Hoffman, R. E.; De Simone, A.; Duignan, T. T.; Nau, W. M. Nat. Chem. 2018, 10, 1252.

(72) Breslow, R.; Zhu, Z. N. J. Am. Chem. Soc. 1995, 117, 9923.

(73) Woodward, R. B.; Katz, T. J. Tetrahedron 1959, 5, 70.

(74) Pauling, L. Nature 1948, 161, 707.

(75) Yoshizawa, M.; Takeyama, Y.; Kusukawa, T.; Fujita, M. Angew. Chem. Int. Ed. 2002, 41, 1347. 
(76) Fiedler, D.; van Halbeek, H.; Bergman, R. G.; Raymond, K. N. J. Am. Chem. Soc. 2006, 128, 10240.

(77) Reinhoudt, D. N.; Crego-Calama, M. Science 2002, 295, 2403.

(78) Koblenz, T. S.; Wassenaar, J.; Reek, J. N. H. Chem. Soc. Rev. 2008, 37, 247.

(79) Hastings, C. J.; Pluth, M. D.; Bergman, R. G.; Raymond, K. N. J. Am. Chem. Soc. 2010, 132, 6938.

(80) Jeong, K. S.; Go, Y. B.; Shin, S. M.; Lee, S. J.; Kim, J.; Yaghi, O. M.; Jeong, N. Chem. Sci. $2011,2,877$.

(81) Hilvert, D.; Hill, K. W.; Nared, K. D.; Auditor, M. T. M. J. Am. Chem. Soc. 1989, 111, 9261.

(82) Hart-Cooper, W. M.; Zhao, C.; Triano, R. M.; Yaghoubi, P.; Ozores, H. L.; Burford, K. N.;

Toste, F. D.; Bergman, R. G.; Raymond, K. N. Chem. Sci. 2015, 6, 1383.

(83) Moghaddam, S.; Yang, C.; Rekharsky, M.; Ko, Y. H.; Kim, K.; Inoue, Y.; Gilson, M. K. J. Am. Chem. Soc. 2011, 133, 3570.

(84) Alternatively, the $k_{\text {cat }}$ value can also be directly compared with the experimental pseudounimolecular rate constant for dimerization of CPD in the neat liquid, which is $8 \times 10^{-6} \mathrm{~s}^{-1}$ when fitted from the initial rate determined by UV spectrophotometry (see Figure S6). A unimolecular rate enhancement factor of ca. 40000 is then obtained for the catalyzed versus uncatalyzed reactions, which corresponds to a transition-state stabilization of ca. $6 \mathrm{kcal} \mathrm{mol}^{-1}$, according to $\mathrm{R} T \ln \left(k_{\text {cat }} / k_{\text {uncat }}\right)$. This value would then compare with a DFT-calculated stabilization by $-4.3 \mathrm{kcal}$ $\mathrm{mol}^{-1}$, as all pertinent values for the reaction of free $\operatorname{CPD}\left(T \Delta S^{\ddagger}, \Delta G^{\ddagger}\right)$ would need to be lowered by $1.5 \mathrm{kcal} \mathrm{mol}^{-1}$ to account for the 11.9 times higher CPD concentration in the neat liquid than in the standard $1 \mathrm{M}$ state $(-\mathrm{R} T \ln (11.9))$.

(85) Mecozzi, S.; Rebek J. Jr Chem. Eur. J. 1998, 4, 1016.

(86) Mohanty, J.; Nau, W. M. Angew. Chem. Int. Ed. 2005, 44, 3750.

(87) Márquez, C.; Nau, W. M. Angew. Chem. Int. Ed. 2001, 40, 4387.

(88) Raistrick, B.; Sapiro, R. H.; Newitt, D. M. J. Chem. Soc. 1939, 1761.

(89) Walling, C.; Naiman, M. J. Am. Chem. Soc. 1962, 84, 2628.

(90) Sherman, J. C.; Cram, D. J. J. Am. Chem. Soc. 1989, 111, 4527.

(91) Cram, D. J. Nature 1992, 356, 29. 
(92) Garel, L.; Dutasta, J. P.; Collet, A. Angew. Chem. Int. Ed. 1993, 32, 1169.

(93) Conn, M. M.; Rebek J. Jr Chem. Rev. 1997, 97, 1647.

(94) Ajami, D.; Tolstoy, P. M.; Dube, H.; Odermatt, S.; Koeppe, B.; Guo, J.; Limbach, H. H.; Rebek J. Jr Angew. Chem. Int. Ed. 2011, 50, 528.

(95) Sahu, D.; Ganguly, B. Tetrahedron Lett. 2013, 54, 5246.

(96) Young, T. A.; Martí-Centelles, V.; Wang, J.; Lusby, P. J.; Duarte, F. J. Am. Chem. Soc. 2020, $142,1300$.

(97) Berta, D.; Szabó, I.; Scherman, O. A.; Rosta, E. Front. Chem. 2020, 8.

(98) Goehry, C.; Besora, M.; Maseras, F. ACS Catal. 2015, 5, 2445.

(99) Carlquist, P.; Maseras, F. Chem. Commun. 2007, 748.

(100) Guner, V. A.; Khuong, K. S.; Houk, K. N.; Chuma, A.; Pulay, P. J. Phys. Chem. A 2004, 108, 2959.

(101) Márquez, C.; Hudgins, R. R.; Nau, W. M. J. Am. Chem. Soc. 2004, 126, 5806.

(102) Gao, S.; Simon, S. L. Thermochim. Acta 2014, 589, 241.

(103) Ben-Naim, A. J. Phys. Chem. 1978, 82, 792.

(104) Jeon, W. S.; Moon, K.; Park, S. H.; Chun, H.; Ko, Y. H.; Lee, J. Y.; Lee, E. S.; Samal, S.; Selvapalam, N.; Rekharsky, M. V.; Sindelar, V.; Sobransingh, D.; Inoue, Y.; Kaifer, A. E.; Kim, K. J. Am. Chem. Soc. 2005, 127, 12984. 